\title{
Effects of Method of Presynchronization and Source of Selenium on Uterine Health and Reproduction in Dairy Cows
}

\author{
H. M. Rutigliano, ${ }^{*}$ F. S. Lima, $†$ R. L. A. Cerri, L. F. Greco, $†$ J. M. Vilela, $†$ V. Magalhães, ${ }^{*}$ F. T. Silvestre, $\dagger$ \\ W. W. Thatcher, $†$ and J. E. P. Santos ${ }^{1}$ \\ *School of Veterinary Medicine, University of California, Davis 95616 \\ †Department of Animal Sciences, University of Florida, Gainesville 32611
}

\begin{abstract}
The objectives of this study were to evaluate the effects of method of presynchronization and source of supplemental Se on uterine health and reproductive performance of lactating dairy cows. Holstein cows (n =512) were assigned randomly to 2 methods of presynchronization, Presynch (2 $\mathrm{PGF}_{2 a}$ given $14 \mathrm{~d}$ apart) or CIDR-PS (controlled internal drug releasing inserted for $7 \mathrm{~d}$ with an injection of $\mathrm{PGF}_{2 \alpha}$ at removal) and 2 sources of Se, sodium selenite (SS) or selenized yeast (SY) supplemented at $0.3 \mathrm{mg} / \mathrm{kg}$ from $25 \mathrm{~d}$ before calving to $80 \mathrm{~d}$ in milk (DIM) arranged in a $2 \times 2$ factorial. Cows were inseminated following the Ovsynch protocol (d $0 \mathrm{GnRH}$, d $7 \mathrm{PGF}_{2 \alpha}$, d $9 \mathrm{GnRH}$, timed artificial insemination (AI) $12 \mathrm{~h}$ after the final $\mathrm{GnRH}$ ) starting at 12 and $3 \mathrm{~d}$ after Presynch and CIDR-PS, respectively. Cows were diagnosed for pregnancy at 28, 42, and $56 \mathrm{~d}$ after AI. Source of Se did not influence uterine health and resumption of cyclicity, but fewer CIDR-PS than Presynch cows were cyclic at the beginning of the Ovsynch, although differences in the proportion cyclic may have been caused by the timing when corpus luteum evaluations were performed in the different presynchronization treatments. Ovulatory responses were not influenced by source of Se. However, the CIDR-PS increased ovulation to the first $\mathrm{GnRH}$, double ovulation to the final $\mathrm{GnRH}$, and size of ovulatory follicle at $\mathrm{PGF}_{2 a}$ and final GnRH of the Ovsynch, but did not influence ovulation at the final GnRH of the Ovsynch. Concentrations of estradiol during the Ovsynch increased with follicle diameter and were greater for cows receiving CIDR-PS than Presynch, but they were not influenced by source of Se. Pregnancy per AI on d 28 (32.7\%), 42 $(28.5 \%)$, and $56(25.9 \%)$ after AI, and pregnancy loss (20.5\%) from 28 to $56 \mathrm{~d}$ were not influenced by source of Se or method of presynchronization. Although cows
\end{abstract}

Received January 7, 2008.

Accepted May 19, 2008.

${ }^{1}$ Corresponding author: jepsantos@ufl.edu receiving CIDR-PS had an increased incidence of ovulation to the first $\mathrm{GnRH}(73.2$ vs. $57.8 \%)$ and double ovulation to the final GnRH of the Ovsynch (18.7 vs. $9.0 \%$ ), both of which enhanced pregnancy, the CIDRPS protocol did not improve pregnancy per AI or reduce pregnancy loss compared with presynchronization with $\mathrm{PGF}_{2 \alpha}$ alone.

Key words: dairy cow, presynchronization, reproduction, selenium

\section{INTRODUCTION}

The Ovsynch (d 0 GnRH, d $7 \mathrm{PGF}_{2 a}$, d 9 GnRH) timed AI (TAI) protocol is commonly used for reproductive management of lactating dairy cows (Caraviello et al., 2006). The use of this regimen has resulted in acceptable pregnancy per AI with maximum submission to insemination compared with programs aimed at synchronizing estrus rather than controlling ovulation (Pursley et al., 1997). The first GnRH injection of the Ovsynch protocol given at random days of the estrous cycle caused ovulation in $64 \%$ of the cows, and this varied according to the stage of the estrous cycle (Vasconcelos et al., 1999). Incidences of ovulation were greater in cows receiving the first $\mathrm{GnRH}$ of the Ovsynch between $d 5$ and 9, and d 17 and 21 of the estrous cycle, than cows between $\mathrm{d} 1$ and 4 , and $\mathrm{d} 10$ and 16 (Vasconcelos et al., 1999). Also, ovulation to the final GnRH injection was not affected by day of the estrous cycle when the Ovsynch protocol was initiated, but it was increased when cows ovulated to the initial GnRH (Vasconcelos et al., 1999). In addition to changes in ovulatory response, day of the cycle when Ovsynch is initiated might also influence the proportion of cows that undergo premature luteolysis, as cows receiving the first GnRH of the Ovsynch after d 10 had increased incidence of premature luteolysis (Vasconcelos et al., 1999). Lack of ovulation to the first $\mathrm{GnRH}$ of the Ovsynch protocol increased the period of dominance of the ovulatory follicle and compromised embryo quality (Cerri et al., 2005), which reduced pregnancy per AI (Chebel et al., 2006). 
To increase ovulation to the first GnRH and limit premature luteolysis during the Ovsynch, a presynchronization regimen using $\mathrm{PGF}_{2 \alpha}$ was developed that optimized reproductive responses to TAI (Moreira et al., 2001); however, response to the presynchronization with $\mathrm{PGF}_{2 a}$ depended upon the cyclic status of the cow. Progesterone inserts induced cyclicity in anovular cows (Chebel et al., 2006) and, when combined with $\mathrm{PGF}_{2 \alpha}$, optimized ovulation to the first GnRH of the Ovsynch protocol (Cerri et al., 2006).

Selenium is a component of several important selenoproteins and enzymes required for antioxidant defense and conversion of inactive thyroid hormone thyroxine $\left(\mathrm{T}_{4}\right)$ to its active form, triiodothyronine $\left(\mathrm{T}_{3}\right)$. Inadequate Se status was associated with increased incidence of uterine problems in cows (Trinder et al., 1973; Harrison et al., 1986), possibly because of impaired neutrophil function (Cebra et al., 2003), which might compromise reproductive performance in dairy cows. Supplementation with selenized yeast (Se-yeast) to cattle increased the concentration of Se in blood compared with sodium selenite (Ortman and Pehrson, 1999) or sodium selenate (Ortman and Pehrson, 1999; Weiss and Hogan, 2005), possibly because of absorption of Se as seleno amino acids such as methionine and cysteine.

It was hypothesized that presynchronization with an intravaginal insert containing progesterone would increase ovulation to the first GnRH of the Ovsynch protocol, and improve establishment and maintenance of pregnancy. It was also hypothesized that replacement of sodium selenite with Se-yeast would improve uterine health and reproductive performance of lactating dairy cows. Therefore, objectives of this study were to evaluate method of presynchronization and source of supplemental Se on uterine health and reproductive performance of lactating dairy cows in California where concentrations of Se in soil and plants are considered adequate.

\section{MATERIALS AND METHODS}

\section{Animals and Housing}

Five hundred eighty-one Holstein cows calving from January to October 2005 were initially enrolled in the study. Cows were housed in 8 pens: 4 in the prepartum and 4 in the postpartum periods. Individual pens were identical in design, size, and number of animals housed. Of the 581 cows initially enrolled, 15 were removed from the study because they remained less than $11 \mathrm{~d}$ in the prepartum diet $(\mathrm{n}=11)$ or aborted $(\mathrm{n}=4)$. In addition, 54 cows did not contribute to the analyses because they left the study or were designated to not be inseminated (Rutigliano et al., 2006). Therefore, 512 cows were utilized for statistical analyses.

The lactating herd size during the study was approximately 890 cows. Cows were milked twice daily and the $3.5 \%$ FCM rolling herd average was $11,630 \mathrm{~kg} / \mathrm{cow}$. For cows enrolled in the study, the mean $( \pm \mathrm{SD})$ and median were, respectively, $2.3 \pm 1.6$ and 2.0 lactations, BCS of $3.57 \pm 0.41$ and 3.50 at study enrollment, and $71.3 \pm 2.9$ and 71.0 DIM at first postpartum AI, and none of them differed $(P>0.40)$ among treatments.

\section{Study Design and Treatments}

Cows were assigned to treatments as a randomized block design in a $2 \times 2$ factorial arrangement of treatments at approximately $25 \pm 3 \mathrm{~d}$ before the expected date of calving (study d $0=$ day of calving). Animals were blocked by parity (primiparous and multiparous) and by expected calving date and, within each block, randomly assigned to 1 of the 4 treatments. Treatments were 2 methods of presynchronization and 2 sources of dietary Se. Cows enrolled in the presynchronization with $\mathrm{PGF}_{2 \alpha}$ (Moreira et al., 2001) received 2 s.c. injections of $25 \mathrm{mg}$ of $\mathrm{PGF}_{2 \alpha}$ (dinoprost tromethamine; Lutalyse sterile solution, Pfizer Animal Health, New York, NY), on study d 37 and 51 (Presynch; 164 multiparous and 96 primiparous cows). Cows in the progesterone insert presynchronization (CIDR-PS; 165 multiparous and 87 primiparous cows) received a controlled internal drug releasing device (Eazi-Breed CIDR; Pfizer Animal Health) containing $1.38 \mathrm{~g}$ of progesterone from study d 53 to 60. At removal of the CIDR, cows received an s.c. injection of $\mathrm{PGF}_{2 \alpha}$ (Figure 1). All cows received TAI on study d 72 following the Ovsynch protocol (Pursley et al., 1997) starting at 12 and $3 \mathrm{~d}$ after the Presynch and CIDR-PS protocols, respectively. For the Ovsynch protocol, cows received an i.m. injection of $100 \mu \mathrm{g}$ of GnRH (gonadorelin diacetate tetrahydrate, Cystorelin; Merial Ltd., Iselin, NJ), followed $7 \mathrm{~d}$ later by an s.c. injection of $25 \mathrm{mg}$ of $\mathrm{PGF}_{2 \mathrm{a}}$, a second i.m. injection of $100 \mu \mathrm{g}$ of GnRH $48 \mathrm{~h}$ later, and AI $12 \mathrm{~h}$ after the final injection of $\mathrm{GnRH}$.

In addition, half of the cows in each presynchronization treatment were supplemented with Se in the pre- and postpartum diets at $0.3 \mathrm{mg} / \mathrm{kg}$ of diet DM as sodium selenite (SS; 164 multiparous and 92 primiparous cows) or as Se-yeast (SY; Sel-Plex, Alltech Biotechnology, Nicholasville, KY; 165 multiparous and 91 primiparous cows). The experimental design resulted in 4 treatments in a $2 \times 2$ factorial arrangement with the following number of cows: SS-Presynch = 126; SSCIDR-PS = 130; SY-Presynch = 134; and SY-CIDR-PS $=122$. 

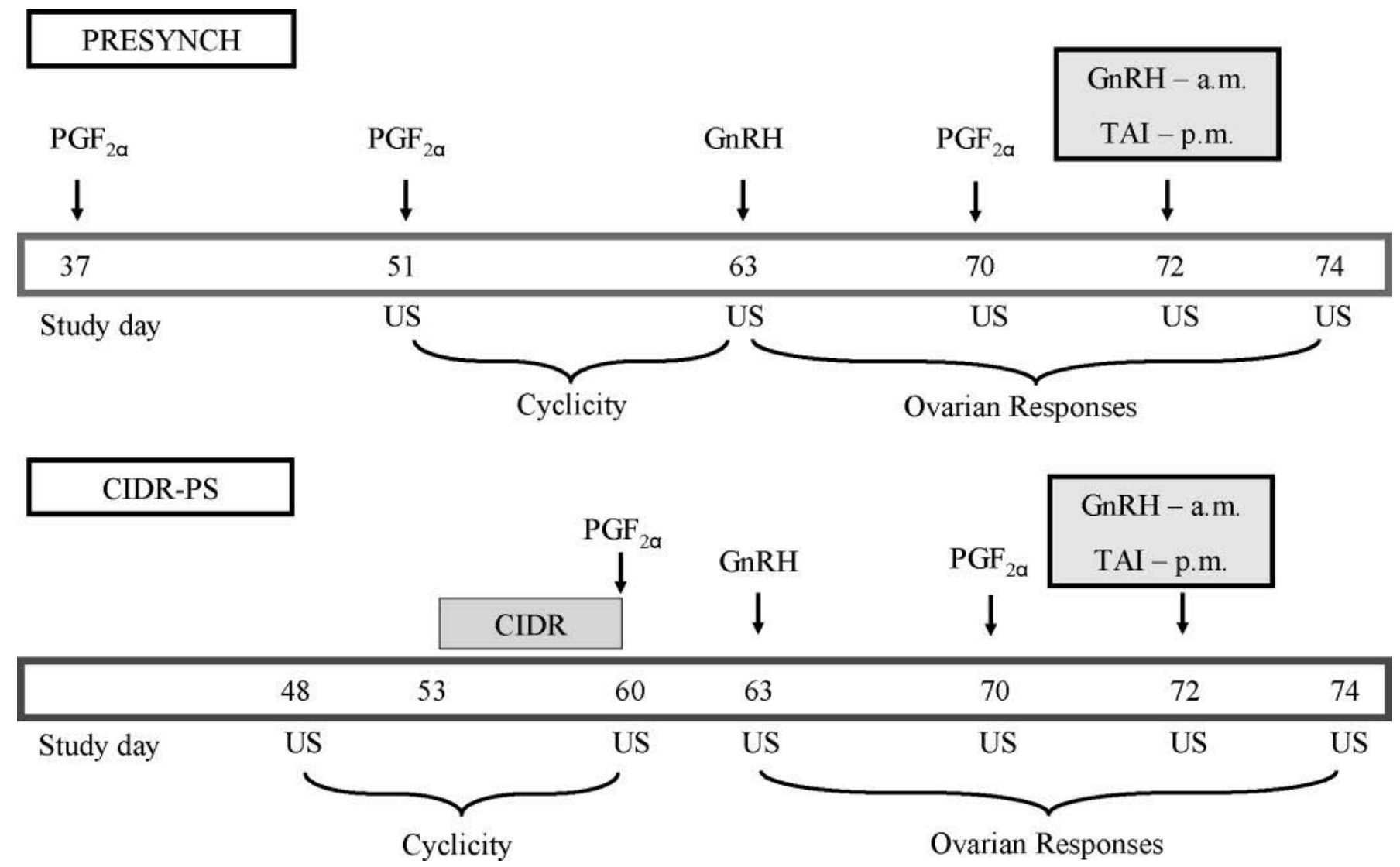

Figure 1. Diagram of presynchronization treatments. Cows in the Presynch treatment received 2 injections of $25 \mathrm{mg}$ of PGF $2 a$ on study d 37 and 51. Cows in the CIDR-PS received a controlled internal drug releasing insert (CIDR) containing $1.38 \mathrm{~g}$ of progesterone for $7 \mathrm{~d}$ and an injection of $\mathrm{PGF}_{2 \alpha}$ on the day of insert removal. All cows received $\mathrm{AI}$ at a fixed time on study d 72 after completion of the Ovsynch protocol starting at 12 or $3 \mathrm{~d}$ after the presynchronization with the Presynch and CIDR-PS protocols, respectively. Ovsynch $=$ injection of $100 \mu \mathrm{g}$ of

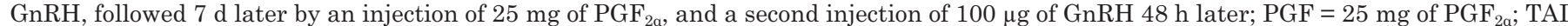
$=$ timed $\mathrm{AI} 12 \mathrm{~h}$ after the second GnRH injection of the Ovsynch protocol; US = ultrasound examination of the ovaries.

\section{Dietary Treatments}

Prepartum cows were fed once daily at $1200 \mathrm{~h}$ and lactating cows twice daily immediately after milking at 0600 and 1600 h. Prepartum and lactation diets were formulated using the CPM-Dairy cattle ration analyzer (Cornell-Penn-Miner, Ver. 3.0.8) to meet or exceed the nutrient requirements set forth by the NRC (2001) for prepartum Holstein cows weighing $670 \mathrm{~kg}$ and consuming $12 \mathrm{~kg}$ of DM in the last $3 \mathrm{wk}$ of gestation, and for lactating Holsteins weighing $630 \mathrm{~kg}$, consuming $24 \mathrm{~kg}$ of DM, and producing $45 \mathrm{~kg} / \mathrm{d}$ of milk containing $3.5 \%$ fat and $3.1 \%$ true protein in the first $80 \mathrm{~d}$ of lactation. Diets were formulated to differ only in the source of supplemental Se, which was the only ingredient incorporated separately into the SS and SY TMR (Table 1). Detailed description of the dietary ingredients and nutrient composition of TMR and ingredients is provided elsewhere (Rutigliano et al., 2006). Dietary treatments and cows were switched among pens such that all pens received both SS and SY to avoid pen effects on treatment responses and to allow cow as the experimental unit.

The expected daily intake of supplemental Se was approximately $4 \mathrm{mg}$ prepartum and $7 \mathrm{mg}$ postpartum. Dietary treatments lasted from $25 \pm 3 \mathrm{~d}$ before expected calving (study day -25) to $80 \mathrm{~d}$ postpartum (study d 80). After that, all cows were fed the SS ration.

\section{Evaluation of Subclinical Endometritis}

Cows on study d $35 \pm 3$ were evaluated for uterine health based on cytologic examination of uterine flush. Briefly, a Foley catheter was introduced into the previously pregnant uterine horn and $20 \mathrm{~mL}$ of sterile saline solution was infused and aspirated. The aspirated fluid was placed in ice, transported to the laboratory, and centrifuged at $750 \times \mathrm{g}$ for $10 \mathrm{~min}$ and the supernatant 
discarded. The pellet was resuspended with $2 \mathrm{~mL}$ of saline, and an aliquot of $20 \mu \mathrm{L}$ was pipetted onto a glass slide and smeared in 2 slides per flush. Smears were air-dried and stained using a Diff-Quick (Fisher Diagnostics, Middletown, VA) stain. Slides were examined and number of total leukocytes, epithelial endometrial cells, and neutrophils were counted to complete 100 cells per slide, and the percentage of neutrophils was calculated. Subclinical endometritis was defined when the proportion of neutrophils $\geq 18 \%$ (Kasimanickam et al., 2004).

\section{Ovarian Ultrasonography, Classification of Anovular Cows, and Ovulatory Responses}

Transrectal ultrasonography of the ovaries was performed using a portable ultrasound equipped with a 7.5-MHz linear probe (Sonovet 2000, Universal Medical System, Bedford Hills, NY) on study d 51 and 63, and on study d 48 and 60 in the Presynch and CIDRPS treatments, respectively, for determination of cyclic status. Cows with at least one ovary bearing a corpus luteum (CL) in any of the 2 ultrasonographic examina-

Table 1. Ingredient composition of diets and mixture of grains and nutrient content of diets

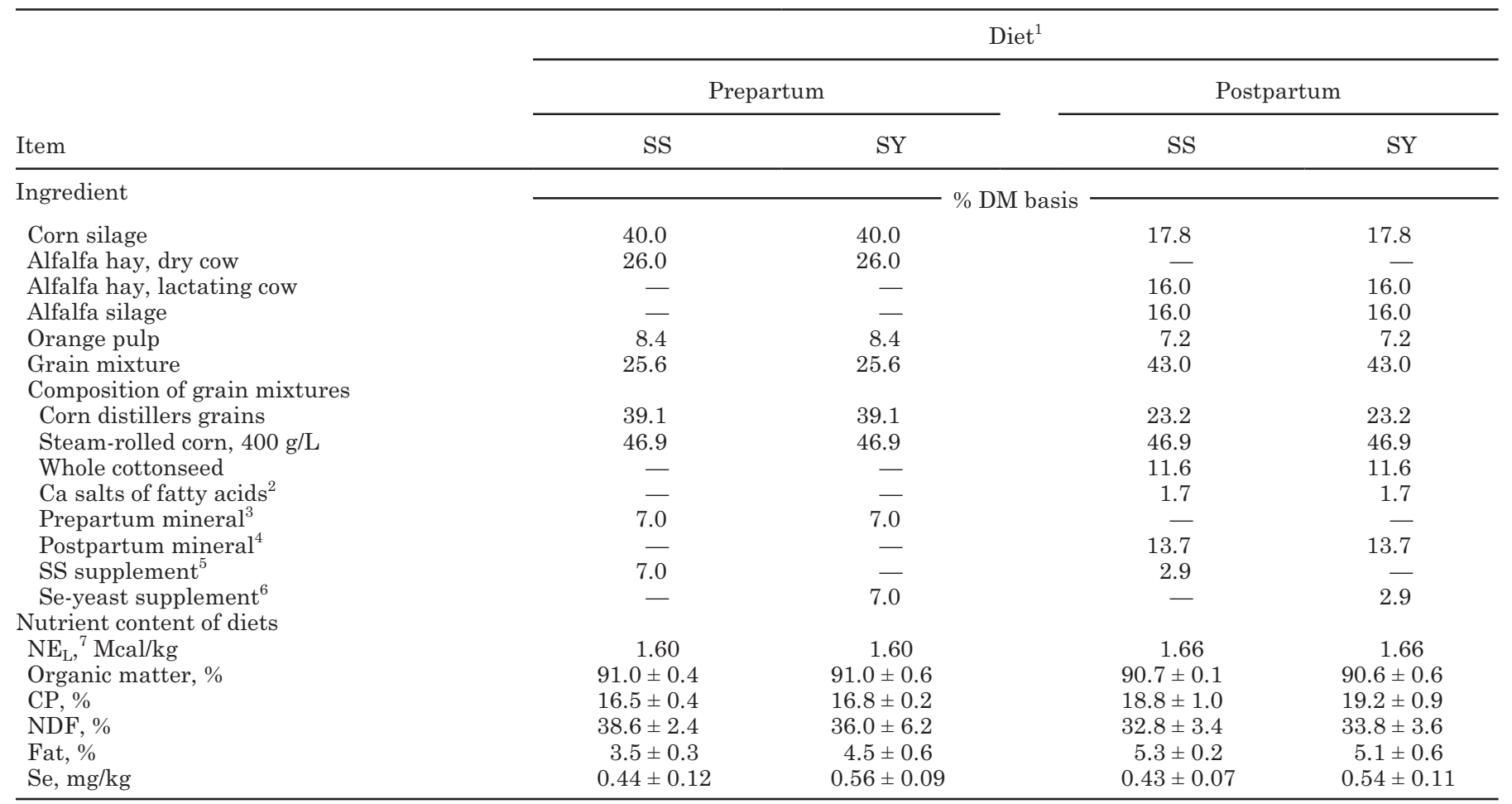

${ }^{1} \mathrm{SS}=$ sodium selenite; $\mathrm{SY}=$ selenium yeast. Prepartum diets were fed during the last $25 \mathrm{~d}$ of gestation; postpartum diets were fed during the first $80 \mathrm{~d}$ of lactation.

${ }^{2}$ Ener GI Transition Formula (Virtus Nutrition LLC, Fairlawn, OH).

${ }^{3}$ Contains (DM basis) 32.1\% anhydrous calcium chloride, 32.1\% anhydrous magnesium sulfate, 4.9\% magnesium oxide, 4.4\% Zinpro 4-Plex (mixture of Zn methionine, Mn methionine, Cu lysine, and Co glucoheptonate; Zinpro Co., Eden Prairie, MN), 17.3\% Diamond V XP (culture of Saccharomyces cerevisiae; Diamond V Mills, Cedar Rapids, IA), and a mixture of iodine and vitamins. Supplement contained (DM basis): $13.6 \% \mathrm{Ca}, 0.1 \% \mathrm{P}, 8.2 \% \mathrm{Mg}, 0.2 \% \mathrm{~K}, 8.1 \% \mathrm{~S}, 0.04 \% \mathrm{Na}, 23.71 \% \mathrm{Cl}$; and (per kg) $1,240 \mathrm{mg}$ of $\mathrm{Zn}, 430 \mathrm{mg}$ of $\mathrm{Cu}, 690 \mathrm{mg}$ of $\mathrm{Mn}, 86 \mathrm{mg}$ of Co, 5.5 $\mathrm{mg}$ of I, 210,000 IU of vitamin A, 40,000 IU of vitamin D, and 12,000 IU of vitamin E.

${ }^{4}$ Contains (DM basis) 23.8\% Pro-Lak (blend of marine and animal by-products; H. J. Baker \& Bro. Inc., Stamford, CT), 52.2\% Amino Plus (lignosulfonate treated soybean meal; Ag Processing Inc., Emmetsburg, IA), 0.36\% Alimet (hydroxy methyl-thio butanoic acid; Novus International Inc., St. Louis, MO), 0.36\% Smartamine M (polymer-protected D,L-methionine, Adisseo Inc., Alpharetta, GA), 2.85\% Diamond V XP, $13.1 \%$ sodium bicarbonate, $2.61 \%$ dicalcium phosphate, $4.00 \%$ magnesium oxide, $0.71 \%$ Zinpro 4 -Plex, and $0.024 \%$ zinc sulfate, and a mixture of iodine and vitamins. Supplement contained (DM basis): $44 \% \mathrm{CP}, 2.45 \% \mathrm{Ca}, 1.66 \% \mathrm{P}, 3.00 \% \mathrm{Mg}, 3.18 \% \mathrm{~K}, 0.76 \% \mathrm{~S}, 3.70 \% \mathrm{Na}$, $0.21 \% \mathrm{Cl}$; and (per kg) $515 \mathrm{mg}$ of $\mathrm{Zn}, 116 \mathrm{mg}$ of Cu, $525 \mathrm{mg}$ of Mn, $12 \mathrm{mg}$ of Co, $9.5 \mathrm{mg}$ of I, 50,000 IU of vitamin A, 11,000 IU of vitamin D, and 500 IU of vitamin E.

${ }^{5}$ Contains (DM basis) 1,350 mg/kg of sodium monensin and $19 \mathrm{mg} / \mathrm{kg}$ of Se from sodium selenite with corn germ meal as carrier.

${ }^{6}$ Contains (DM basis) 1,350 mg/kg of sodium monensin and $19 \mathrm{mg} / \mathrm{kg}$ of Se from Sel-Plex (selenized yeast; Alltech Biotechnology Inc., Nicholasville, KY) with corn germ meal as carrier.

${ }^{7} \mathrm{NE}_{\mathrm{L}}$ calculated from NRC (2001) based on nutrient composition of ingredients and the average DMI in the prepartum (12 kg/d) and lactation $(24 \mathrm{~kg} / \mathrm{d})$ periods (Rutigliano et al., 2006). 
tions were classified as cyclic, whereas those without a CL in both examinations were classified as anovular.

Ovaries also were examined during all injections of the Ovsynch protocol and again $48 \mathrm{~h}$ after the final injection of GnRH. Maps of the ovaries were drawn, and size and location of follicles $>8 \mathrm{~mm}$ and CL were recorded. Cows were classified as ovulating to the first GnRH of the Ovsynch protocol when they had a follicle $\geq 10 \mathrm{~mm}$ in diameter on the day of $\mathrm{GnRH}$ and a new CL was detected the day the $\mathrm{PGF}_{2 \alpha}$ was administered. Ovulation to the final GnRH of the Ovsynch protocol was determined when a follicle $\geq 10 \mathrm{~mm}$ in diameter detected at the time of the injection was not observed $48 \mathrm{~h}$ later.

\section{Blood Sampling}

Blood was sampled by puncture of the median coccygeal vein or artery using evacuated tubes (Becton Dickinson, Franklin Lakes, NJ) with $\mathrm{K}_{2}$ EDTA for plasma separation. Samples were immediately placed in ice and transported to the laboratory within $5 \mathrm{~h}$ of collection. Blood tubes were centrifuged at 2,000 $\times \mathrm{g}$ for 15 min, and plasma was frozen at $-25^{\circ} \mathrm{C}$ until analyses.

\section{Concentrations of Se and Estradiol in Plasma and Glutathione Peroxidase Activity in Plasma}

Concentrations of Se in plasma collected from 30 cows fed SS and 25 fed SY were measured on study days $-45,0,21,42$, and 63. Analysis of Se in blood plasma was performed by a fluorometric method (Phyllis and Ullrey, 1978). Glutathione peroxidase (GPx) activity was determined in plasma on study $\mathrm{d} 0$ and 42 with a GPx assay kit (Cayman Chemical Company, Ann Arbor, MI).

Concentrations of estradiol were measured in plasma collected from 50 cows, 18 primiparous and 32 multiparous, with the following distribution per treatment: 11 SS-Presynch, 12 SY-Presynch, 14 SS-CIDR-PS, and 13 SY-CIDR-PS. Plasma samples were collected on the day of $\mathrm{PGF}_{2 \alpha}$ and $48 \mathrm{~h}$ later at final $\mathrm{GnRH}$ of the Ovsynch protocol and analyzed by RIA according to Kirby et al. (1997). Samples were analyzed in triplicate in a single assay and the $\mathrm{CV}$ was $9.2 \%$. Mean sensitivity of the assay, calculated as $2 \mathrm{SD}$ below the mean cpm at maximum binding, was $0.51 \mathrm{pg} / \mathrm{mL}$.

\section{Pregnancy Diagnosis and Calculation of Reproductive Outcomes}

Pregnancy was diagnosed at $28 \mathrm{~d}$ after TAI by ultrasonography of the uterus and its contents and was characterized by visualization of an embryo. Cows diagnosed as pregnant on d 28 were re-examined by palpation per rectum of the uterine contents at 42 and $56 \mathrm{~d}$ after AI. Pregnancy per AI at first and second postpartum AI were calculated as the number of cows that became pregnant divided by the number of inseminated cows for each postpartum AI. Pregnancy loss after first postpartum AI was calculated as the number of cows that lost pregnancy from 28 to $56 \mathrm{~d}$ of gestation divided by the number of pregnant cows on d 28 after TAI.

\section{Resynchronization of Cows and Reinsemination of Nonpregnant Cows After First Al and Pregnancy Diagnosis}

After the first AI, estrus was observed once daily based on removal of tail chalk (All-Weather Paintstik, LA-CO Industries, Chicago, IL), and cows were reinseminated upon detection of estrus in the morning. Cows not reinseminated received an injection of $100 \mu \mathrm{g}$ of GnRH $21 \mathrm{~d}$ after the first TAI and, $7 \mathrm{~d}$ later, those cows found nonpregnant during the ultrasonography received an injection of $25 \mathrm{mg}$ of $\mathrm{PGF}_{2 \alpha}$ and the Ovsynch protocol was completed. After the second postpartum AI, pregnancy was diagnosed by palpation per rectum of the uterine contents at $42 \pm 3 \mathrm{~d}$ after AI. Of the cows reinseminated after the first postpartum AI, $126(37.5 \%)$ were inseminated based on detection of spontaneous estrus and $210(62.5 \%)$ based on TAI, and all cows were included in the analysis of pregnancy to second AI.

\section{Body Condition Scoring}

Body condition of all cows was scored at enrollment (study day $-25 \pm 3$ ), at calving, and study d $42 \pm 3,72$ \pm 3 , and $100 \pm 3$. Cows were scored for body condition on a scale of 1 (emaciated) to 5 (obese), with 0.25 -unit increments as described by Ferguson et al. (1994).

\section{Temperature and Humidity Recording and Heat Stress}

Ambient temperature and relative humidity $(\mathbf{R H})$ were recorded hourly by data recorders (Hobo H8 Pro Series, Onset Computer Corp., Bourne, MA), operated by a computer software program (BoxCar Pro 4.0 Starter Kit, Onset Computer Corp.). Temperature and $\mathrm{RH}$ accuracy were within $\pm 0.2^{\circ} \mathrm{C}$ and $\pm 2 \%$, respectively. Two recorders were placed in each study pen at a height of $1.9 \mathrm{~m}$ from the floor and placed under the central shades in the prepartum pens and immediately above the stalls in the lactation pens. The probes recorded data from February to November 2005. The temperature-humidity index (THI) was calculated as: 
$\mathrm{THI}=\mathrm{td}-(0.55-0.55 \mathrm{RH} / 100)(\mathrm{td}-58)$, in which $\mathrm{td}$ is the temperature (in ${ }^{\circ} \mathrm{F}$ ) and $\mathrm{RH}$ is expressed as a percentage (NOAA, 1976). For each 24 -h period, average daily mean and maximum temperature, $\mathrm{RH}$, and THI were determined.

\section{Statistical Analyses}

Binary data such as cyclic status, subclinical endometritis, ovulation, double ovulation, pregnancy per AI, and pregnancy loss were analyzed by logistic regression using the LOGISTIC procedure of SAS (SAS Inst. Inc., Cary, NC). A backward stepwise regression was utilized, and all models included the effects of method of presynchronization, source of Se, interaction between method of presynchronization and source of Se, parity, heat stress, interaction between source of Se and parity, interaction between source of Se and heat stress, interaction between method of presynchronization and parity, interaction between method of presynchronization and heat stress, and other explanatory variables as appropriate. Variables were sequentially removed from the model by the Wald's statistic criterion if $P$ $>0.10$; however, method of presynchronization and source of Se were forced in the final model. Adjusted odds ratio (AOR) and the $95 \%$ confidence interval (CI) were calculated. For second postpartum AI, type of insemination, either at spontaneous estrus or TAI was also included in the model.

Diameters of the ovulatory follicle at the injection of $\mathrm{PGF}_{2 \mathrm{a}}$ and at final $\mathrm{GnRH}$ of the Ovsynch protocol were analyzed by ANOVA using the GLM procedure (SAS Inst. Inc.). The model included the effects of method of presynchronization, source of Se, interaction between method of presynchronization and source of Se, parity, and other explanatory variables as appropriate. Concentrations of Se and estradiol in plasma were analyzed by ANOVA for repeated measures with the MIXED procedure (SAS Inst. Inc.). For plasma Se, the model included the effects of source of Se, day in the study, and interaction between source of Se and day in the study, the initial Se concentration on study d -45 as covariate. Cow nested within source of Se was the random experimental error. Covariance structure was tested and that with the smallest Schwarz Bayesian criterion was chosen for each statistical model. For concentrations of estradiol, the statistical model included the effects of method of presynchronization, source of Se, interaction between method of presynchronization and source of Se, hour of blood collection, interaction between method of presynchronization and hour of blood collection, interaction between source of Se and hour of blood collection, interaction between method of presynchronization and source of Se and hour of blood collection, parity, and cyclic status. Cow nested within treatment was the random error for the model. The covariance with the smallest Schwarz Bayesian criterion was selected for the repeated statement of the model. Treatment differences with $P \leq 0.05$ were considered significant and differences at $0.05<P \leq 0.10$ were designated as tendency.

\section{RESULTS}

Because none of the variables analyzed presented an interaction between method of presynchronization and source of Se, results are presented separately for the effects of method of presynchronization and source of Se.

The mean $( \pm \mathrm{SEM})$ and median days cows were fed the prepartum diets were, respectively, $24.7 \pm 0.3$ and 24 for SS and $24.9 \pm 0.4$ and $25 \mathrm{~d}$ for SY treatment. Concentrations of Se in plasma were similar $(P=0.38)$ for cows fed SS $(0.101 \pm 0.005 \mu \mathrm{g} / \mathrm{mL})$ and $\mathrm{SY}(0.107 \pm$ $0.005 \mu \mathrm{g} / \mathrm{mL})$. Concentrations of Se increased $(P=0.01)$ with days in the study, but no interaction between dietary treatment and day in the study was observed. Similarly, GPx activity in plasma did not differ $(P=$ 0.59 ) between sources of Se and averaged $594.0 \pm 18.5$ and $604.2 \pm 20.0 \mathrm{nmol} / \mathrm{mL}$ per min for SS and SY, respectively.

Weekly mean and maximum temperatures, relative humidity, and THI were all similar among pre- and postpartum pens. Based on the mean daily THI $\geq 72$ (Armstrong, 1994), cows were subjected to the greatest heat stress in July and August (Figure 2). When the average maximum daily THI was considered, cows began to be exposed to some heat stress in May and continued to be exposed through September.

\section{BCS}

The mean BCS during the study was not different between presynchronization protocols. Source of Se did not influence $(P=0.45) \mathrm{BCS}$ in the first 100 DIM; BCS averaged $3.07 \pm 0.02$ and $3.08 \pm 0.02$ in cows fed SS and SY, respectively. Cows lost BCS in the first 48 to $70 \mathrm{~d}$ postpartum and started to regain at $100 \mathrm{~d}$ postpartum, but no interaction between source of Se and day postpartum on BCS was observed. Multiparous cows had a lesser $(P=0.02)$ mean BCS during the study period compared with primiparous cows $(3.05 \pm 0.01$ vs. 3.10 $\pm 0.02)$.

\section{Subclinical Endometritis}

Source of Se had no effect on the prevalence of subclinical endometritis at 35 DIM, and it affected 18.1 


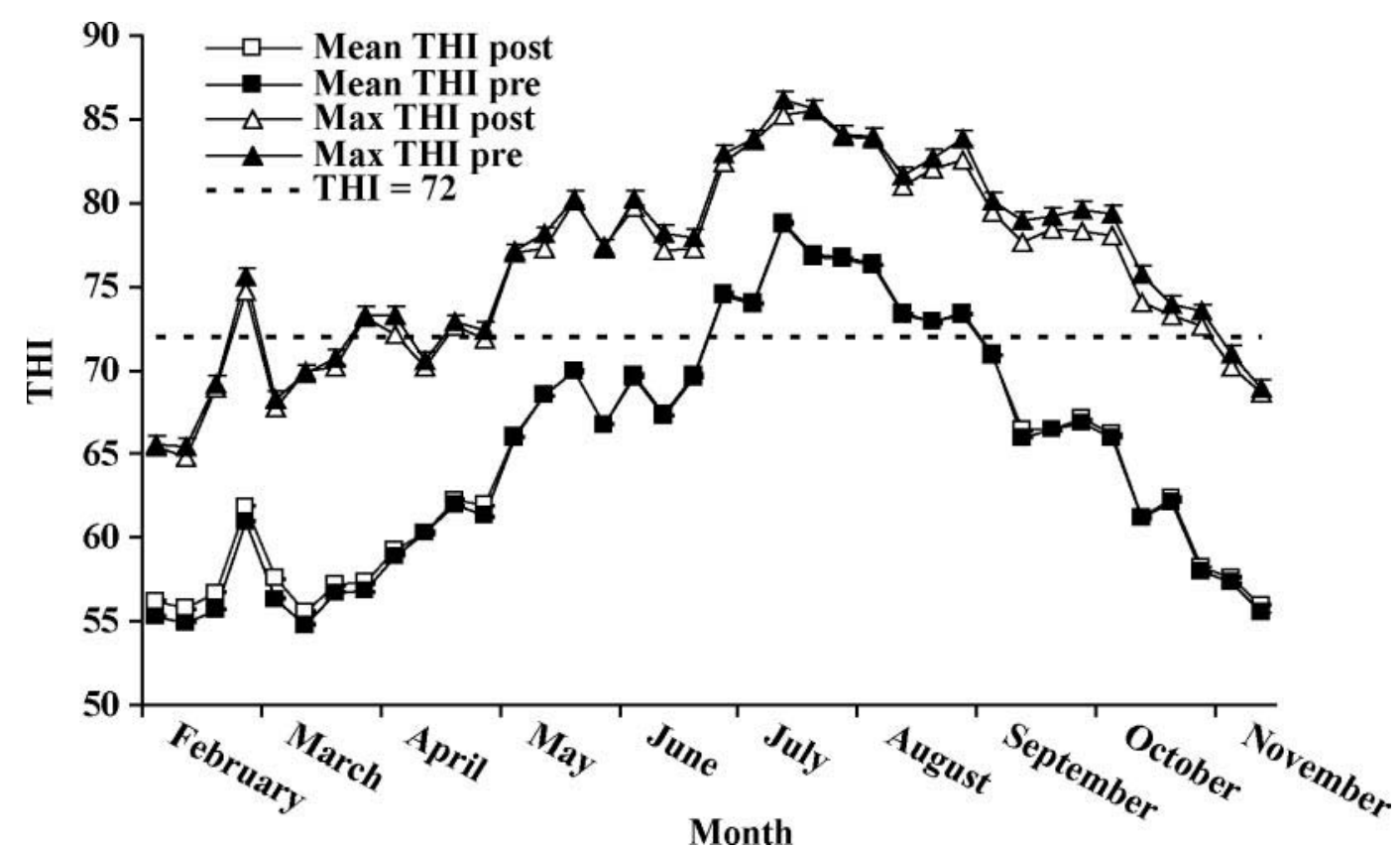

Figure 2. Temperature-humidity index (THI; NOAA, 1976) during the different months of the study. Mean THI post = mean daily THI in the postpartum pens; Mean THI pre = mean daily THI in the prepartum pens; Max THI post = maximum daily THI in the postpartum pens; Max THI pre $=$ maximum daily THI in the prepartum pens. Mean and maximum daily THI differed $(P<0.01)$ among weeks of the study for the pre- and postpartum periods, but not among pens $(P>0.05)$. Cows were exposed to heat stress during the months of July and August based on mean daily THI $\geq 72$ (dashed line indicates THI $=72$ ).

and $18.3 \%$ of SS and SY cows. Prevalence of subclinical endometritis did not differ between presynchronization protocols $($ Presynch $=18.0$ vs. CIDR-PS $=18.4 \%)$ and parity (multiparous $=18.0$ vs. primiparous $=18.5 \%$ ) . Risk of subclinical endometritis tended to increase (AOR $=1.95,95 \% \mathrm{CI}, 0.98$ to $3.89 ; P=0.06)$ in cows that had retained placenta [31.1 (14/45) vs. $17.0 \%(80 / 472)]$, which was defined as presence of fetal membranes 24 $\mathrm{h}$ after calving (Rutigliano et al., 2006). Similarly, risk of subclinical endometritis more than doubled (AOR $=2.12 ; 95 \% \mathrm{CI}, 1.25$ to $3.59 ; P=0.005$ ) in cows with acute puerperal metritis compared with those without puerperal metritis, with the former characterized by foul watery uterine discharge of brownish or reddish color concurrent with rectal temperature $>39.5^{\circ} \mathrm{C}$ (Rutigliano et al., 2006).

\section{Source of Se and Reproductive Responses}

Source of Se had no effect on cyclic status of the cows (Table 2) or any of the ovarian responses evaluated during the Ovsynch protocol (data not shown). Pregnancy per $\mathrm{AI}$ evaluated at 28, 42, and $56 \mathrm{~d}$ after first postpartum AI were similar for cows fed SS and SY. Similarly, source of Se had no effect on pregnancy loss after the first $\mathrm{AI}$ and proportion pregnant at second postpartum AI (Table 2).

\section{Cyclic Status, Ovarian Responses to the Ovsynch Protocol, and Estradiol Concentrations}

A greater $(P=0.02)$ proportion of cows that received Presynch were cyclic than those receiving CIDR-PS based on the presence of a CL during ultrasound at differing times during the 2 presynchronization treatments (Table 3). Cyclic status was not affected by occurrence of puerperal metritis, retained placenta, and changes in BCS from calving to AI, but multiparous cows were 2.19 times more likely $(P=0.002)$ to be cyclic than primiparous cows (multiparous $=85.1 \%$ vs. primiparous $=76.5 \%$ ), and cows with greater BCS at AI were also more likely $(P=0.002)$ to be cyclic. As BCS at $\mathrm{AI}$ increased from $<2.75$ to between 2.75 and 3.25 and finally to $>3.25$, the proportion of cyclic cows also increased (76.5 vs. 82.1 vs. $95.8 \%$ ).

The proportion of cows with a CL at the time of the $\mathrm{PGF}_{2 \alpha}$ treatment of the Ovsynch protocol was similar between methods of presynchronization (Table 3). Cyclic cows were 3.15 times more likely $(P<0.001)$ to have a CL at time of $\mathrm{PGF}_{2 \alpha}$ of the Ovsynch protocol. The diameters of the ovulatory follicle at the moment of the $\mathrm{PGF}_{2 \alpha}$ and final $\mathrm{GnRH}$ injections of the Ovsynch protocol were larger $(P=0.006)$ for cows in the CIDRPS compared with those in the Presynch protocol. Cows in the CIDR-PS had greater incidences of ovulation to 
Table 2. Effect of source of Se on reproductive responses of dairy cows

\begin{tabular}{|c|c|c|c|c|c|}
\hline \multirow[b]{2}{*}{ Item } & \multicolumn{2}{|c|}{ Source of $\mathrm{Se}^{1}$} & \multirow[b]{2}{*}{$\mathrm{AOR}^{2}$} & \multirow[b]{2}{*}{$95 \% \mathrm{CI}^{3}$} & \multirow[b]{2}{*}{$P$-value } \\
\hline & SS & SY & & & \\
\hline Cows, $\mathrm{n}$ & 256 & 256 & - & - & - \\
\hline Cyclic, \% & 79.7 & 84.4 & 0.81 & $0.50,1.30$ & 0.38 \\
\hline \multicolumn{6}{|l|}{ Pregnant, \% } \\
\hline Day 28 & 34.5 & 30.9 & 1.2 & $0.8,1.8$ & 0.40 \\
\hline Day 42 & 30.2 & 26.8 & 1.2 & $0.8,1.9$ & 0.35 \\
\hline Day 56 & 27.8 & 24.0 & 1.3 & $0.8,2.0$ & 0.30 \\
\hline \multicolumn{6}{|l|}{ Pregnancy loss, \% } \\
\hline Day 28 to 56 & 18.8 & 22.4 & 0.7 & $0.3,1.6$ & 0.41 \\
\hline Pregnant at 2 nd $\mathrm{AI},{ }^{4} \%$ & 30.3 & 26.4 & 1.1 & $0.7,1.9$ & 0.65 \\
\hline
\end{tabular}

${ }^{1} \mathrm{SS}=$ sodium selenite; $\mathrm{SY}=$ selenium yeast.

${ }^{2} \mathrm{AOR}=$ adjusted odds ratio; $\mathrm{SY}$ as the reference value.

${ }^{3} \mathrm{CI}=$ confidence interval.

${ }^{4}$ Includes all reinseminated cows.

the first $\operatorname{GnRH}(P<0.001)$ and double ovulation to the final GnRH $(P=0.005)$ of the Ovsynch than Presynch cows, but overall ovulation to the final $\mathrm{GnRH}$ did not differ between methods of presynchronization.

Ovulation to the final GnRH of the Ovsynch protocol was influenced by BCS at AI and ovulation to the first GnRH (Table 4). Cows that ovulated to the first GnRH injection of the Ovsynch protocol were 2.56 times more likely $(P<0.001)$ to ovulate to the final $\mathrm{GnRH}$, whereas cows with a BCS $<2.75$ at AI were less likely $(P=0.04)$ to ovulate to the final $\mathrm{GnRH}$ than those with $\mathrm{BCS} \geq 2.75$. In addition to presynchronization method, multiparous cows were 2.66 times more likely $(P=0.006)$ to have a double ovulation than primiparous cows.

Table 3. Effect of method of presynchronization on ovarian responses to the Ovsynch protocol and reproductive responses

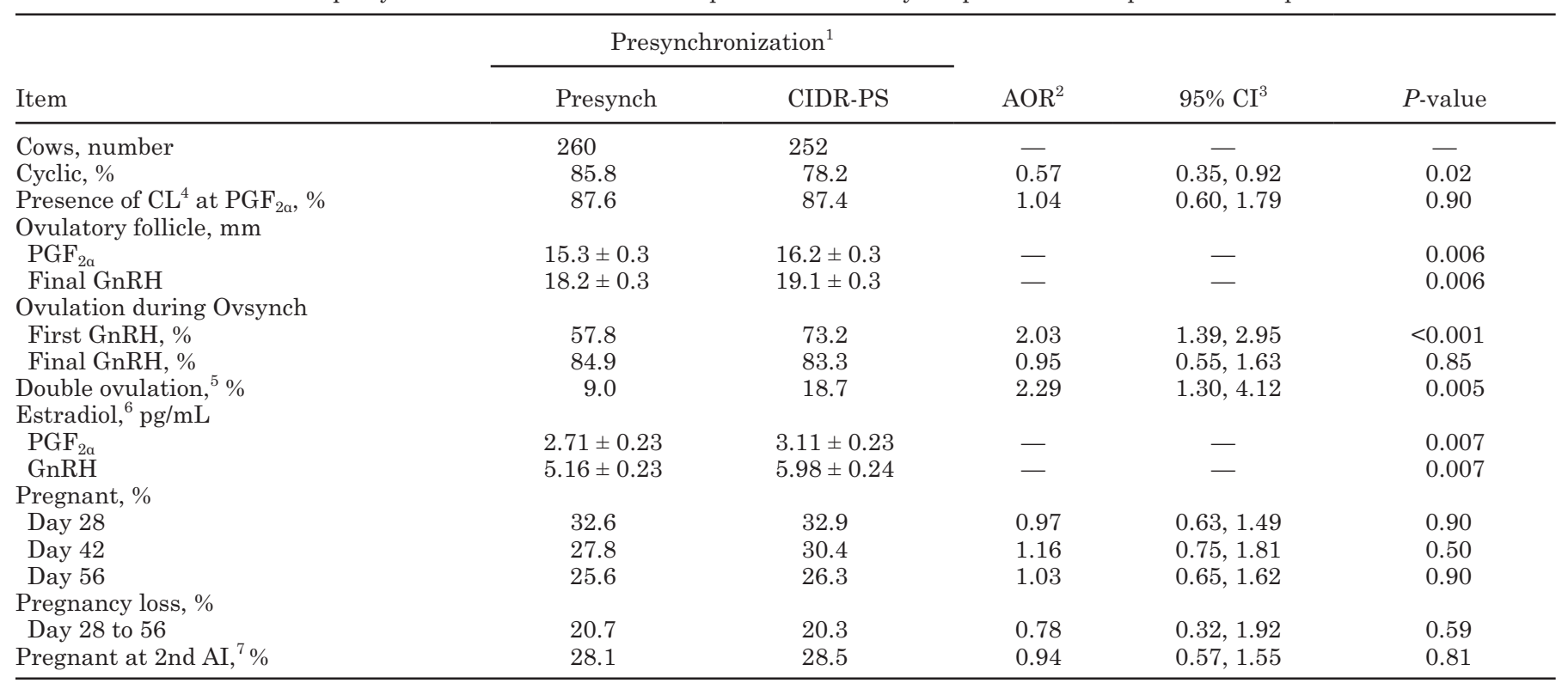

${ }^{1}$ Presynch $=2$ injections of $25 \mathrm{mg}$ of $\mathrm{PGF}_{2 \alpha}$ at 37 and $51 \mathrm{~d}$ postpartum and the Ovsynch program started $12 \mathrm{~d}$ later; CIDR-PS $=$ cows received a controlled internal drug releasing device containing $1.38 \mathrm{~g}$ of progesterone from 53 to $60 \mathrm{~d}$ postpartum with an injection of $\mathrm{PGF}_{2 \alpha}$ at insert removal and the Ovsynch protocol started $3 \mathrm{~d}$ later.

${ }^{2} \mathrm{AOR}=$ adjusted odds ratio; Presynch as the reference value.

${ }^{3} \mathrm{CI}=$ confidence interval.

${ }^{4} \mathrm{CL}=$ corpus luteum.

${ }^{5}$ Percentage of cows responding to the final GnRH injection of the Ovsynch protocol that ovulated 2 follicles within $48 \mathrm{~h}$ of treatment.

${ }^{6}$ Concentrations of estradiol in plasma of 50 cows at the injections of $\mathrm{PGF}_{2 \alpha}$ and final $\mathrm{GnRH}$ of the Ovsynch protocol.

${ }^{7}$ Includes all reinseminated cows. 
Table 4. Risk factors for ovulation within $48 \mathrm{~h}$ of the final $\mathrm{GnRH}$ of the Ovsynch protocol

\begin{tabular}{|c|c|c|c|c|}
\hline Item & Ovulation, \% (n/n) & $\mathrm{AOR}^{1}$ & $95 \% \mathrm{CI}^{2}$ & $P$-value \\
\hline \multicolumn{5}{|l|}{$\mathrm{BCS}$ at $\mathrm{AI}$} \\
\hline$>3.25$ & $91.7(66 / 72)$ & 1.60 & $0.64,3.97$ & 0.04 \\
\hline 2.75 to 3.25 & $88.0(279 / 317)$ & 1.00 & - & \\
\hline$<2.75$ & $79.8(91 / 114)$ & 0.54 & $0.30,0.96$ & \\
\hline \multicolumn{5}{|c|}{ Ovulation to first GnRH } \\
\hline Yes & $90.6(298 / 329)$ & 2.56 & $1.51,4.33$ & $<0.001$ \\
\hline No & $79.3(138 / 174)$ & 1.00 & - & \\
\hline
\end{tabular}

${ }^{1} \mathrm{AOR}=$ adjusted odds ratio.

${ }^{2} \mathrm{CI}=$ confidence interval.

Concentrations of estradiol in plasma were not affected by source of Se and averaged $4.3 \pm 0.17$ and 4.17 $\pm 0.21 \mathrm{pg} / \mathrm{mL}$ during the Ovsynch for SS and SY, respectively; however, cows receiving CIDR-PS had greater $(P$ $=0.007)$ concentrations of estradiol at the injections of $\mathrm{PGF}_{2 \alpha}$ (Table 3). Concentrations of estradiol increased $(P<0.001)$ from $\mathrm{PGF}_{2 \alpha}$ to $48 \mathrm{~h}$ later $(2.91 \pm 0.19$ vs. $5.57 \pm 0.19 \mathrm{pg} / \mathrm{mL})$, but no interaction $(P>0.25)$ was observed between method of presynchronization and source of Se, method of presynchronization and hour after $\mathrm{PGF}_{2 \mathrm{a}}$, and between source of Se and hour after $\mathrm{PGF}_{2 \alpha}$. Parity and cyclic status influenced plasma estradiol concentrations; primiparous cows had greater $(P=0.006)$ concentrations than multiparous cows $(4.56$ \pm 0.20 vs. $3.92 \pm 0.19 \mathrm{pg} / \mathrm{mL}$ ), and concentrations were greater $(P=0.02)$ in cyclic than anovular cows $(4.62 \pm$ 0.13 vs. $3.86 \pm 0.28 \mathrm{pg} / \mathrm{mL}$ ). Plasma estradiol concentrations were related $\left(\mathrm{R}^{2}=40.2 \% ; P<0.001\right)$ to ovulatory follicle diameter in both Presynch and CIDR-PS treatments (Figure 3).

\section{Pregnancy at First and Second Postpartum AI and Pregnancy Loss}

Method of presynchronization did not affect pregnancy after first and second postpartum inseminations or pregnancy loss after first postpartum TAI (Table 3). Subclinical endometritis at $35 \mathrm{~d}$ postpartum negatively affected $(P<0.01)$ pregnancy per AI at all times. On d 28 after AI, cows diagnosed with subclinical endometri-

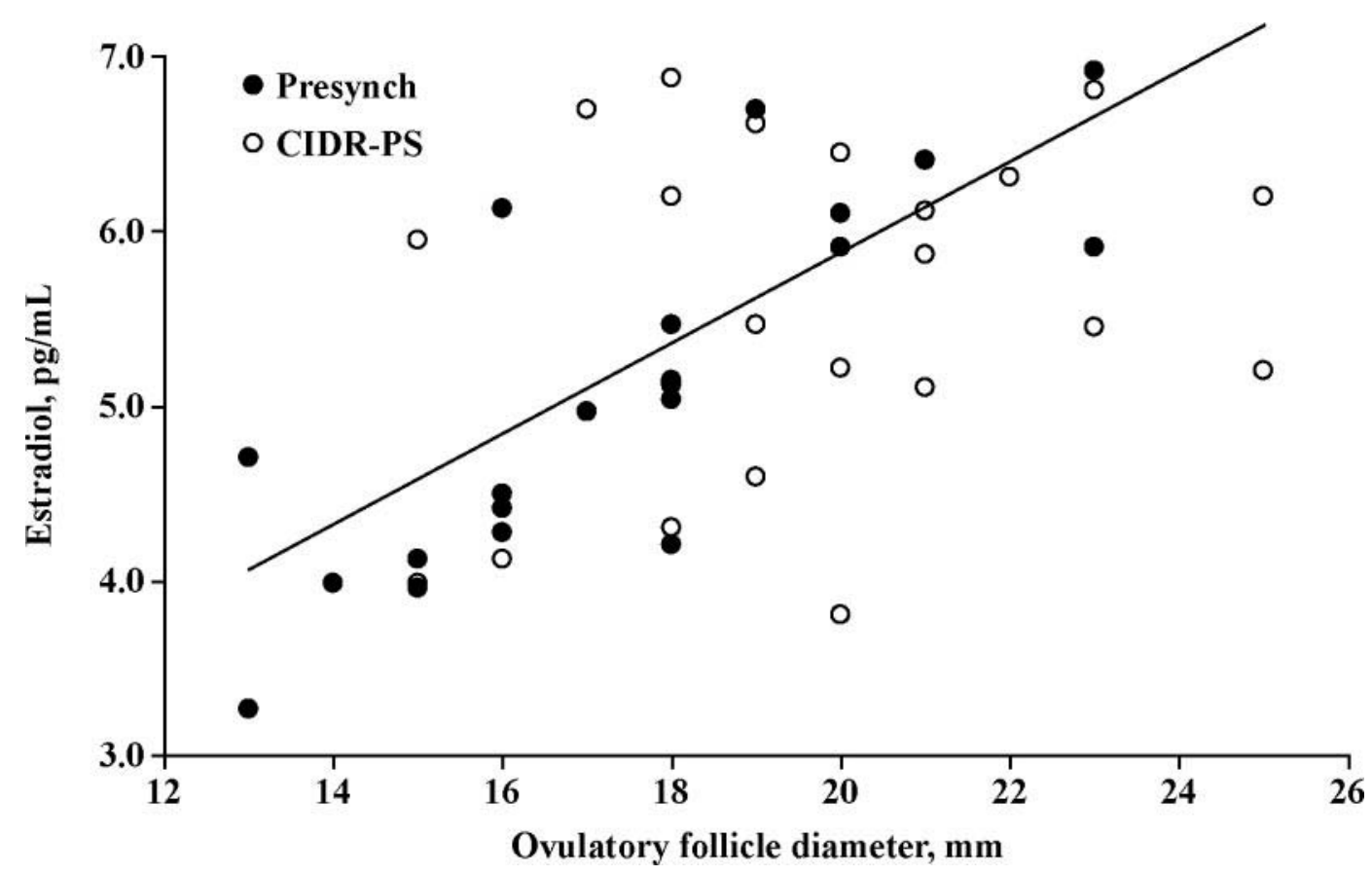

Figure 3. Relationship between ovulatory follicle diameter and estradiol concentrations at the final GnRH of the Ovsynch protocol in cows presynchronized with 2 injections of $\mathrm{PGF}_{2 \alpha} 14 \mathrm{~d}$ apart, with the second injection given $12 \mathrm{~d}$ before the Ovsynch (Presynch), or with a controlled internal drug releasing insert (CIDR) for $7 \mathrm{~d}$ and $\mathrm{PGF}_{2 \alpha}$ at CIDR removal, with the Ovsynch starting $3 \mathrm{~d}$ after CIDR removal (CIDR-PS). Estradiol, $\mathrm{pg} / \mathrm{mL}=0.7029+0.2591 \times$ follicle diameter, $\mathrm{r}^{2}=40.2 \%(P<0.001)$. 
Table 5. Risk factors for pregnancy $28 \mathrm{~d}$ after first postpartum AI

\begin{tabular}{|c|c|c|c|c|}
\hline Item & Pregnant, \% (n/n) & $\mathrm{AOR}^{1}$ & $95 \% \mathrm{CI}^{2}$ & $P$-value \\
\hline \multicolumn{5}{|c|}{ Subclinical endometritis } \\
\hline Yes & $18.3(15 / 82)$ & 0.37 & $0.20,0.69$ & 0.002 \\
\hline No & $35.7(140 / 392)$ & 1.00 & - & \\
\hline \multicolumn{5}{|l|}{ Cyclic } \\
\hline Yes & $34.9(144 / 413)$ & 1.84 & $1.01,3.32$ & 0.04 \\
\hline No & $22.0(18 / 82)$ & 1.00 & - & \\
\hline \multicolumn{5}{|c|}{ Ovulation to first $\mathrm{GnRH}$} \\
\hline Yes & $37.4(122 / 326)$ & 1.73 & $1.09,2.74$ & 0.02 \\
\hline No & $23.7(40 / 169)$ & 1.00 & - & \\
\hline \multicolumn{5}{|c|}{ Ovulation to final GnRH } \\
\hline Yes & $35.4(152 / 430)$ & 2.45 & $1.17,5.15$ & 0.02 \\
\hline No & $15.4(10 / 65)$ & 1.00 & - & \\
\hline \multicolumn{5}{|c|}{ Double ovulation $^{3}$} \\
\hline Yes & $50.0(29 / 58)$ & 2.27 & $1.24,4.15$ & 0.01 \\
\hline No & $33.1(123 / 372)$ & 1.00 & - & \\
\hline \multicolumn{5}{|c|}{ Heat stress ${ }^{4}$} \\
\hline Yes & $8.6(9 / 105)$ & 0.17 & $0.08,0.35$ & $<0.001$ \\
\hline No & $39.2(153 / 390)$ & 1.00 & - & \\
\hline
\end{tabular}

tis were less likely $(P=0.002)$ to be pregnant (Table 5). Cyclic cows had greater $(P=0.005)$ pregnancy per AI than anovular cows. Similarly, cows that ovulated either to the first or to the final GnRH of the Ovsynch protocol had increased pregnancy per AI than those that did not ovulate to GnRH. Of the cows that ovulated within $48 \mathrm{~h}$ of the final $\mathrm{GnRH}$, those experiencing double ovulation were 2.27 times more likely $(P=0.01)$ to become pregnant than single ovulating cows. On the other hand, cows exposed to mean THI $\geq 72$ had a lesser pregnancy per AI. Pregnant cows at $28 \mathrm{~d}$ after first AI ovulated larger $(P=0.003)$ follicles than nonpregnant cows $(19.4 \pm 0.3$ vs. $18.4 \pm 0.2 \mathrm{~mm})$.

Pregnancy loss between 28 and $56 \mathrm{~d}$ of gestation was $20.5 \%$. Cows inseminated with a BCS between
2.75 and 3.25 were less likely $(P=0.04)$ to lose the pregnancy than those inseminated with a BCS $<2.75$, but pregnancy loss did not differ between cows with BCS $>3.25$ and other categories of BCS (Table 6). In addition, cows that ovulated within $48 \mathrm{~h}$ of the final GnRH of the Ovsynch had less $(P=0.05)$ pregnancy loss, whereas cows exposed to heat stress were 7.42 times more likely $(P=0.007)$ to lose their pregnancy than cows not exposed to heat stress at AI.

\section{DISCUSSION}

Previous studies demonstrated that Se deficiency was associated with increased incidence of uterine problems such as retained placenta and poor uterine

Table 6. Risk factors for pregnancy loss from gestation d 28 to 56 after first AI

\begin{tabular}{|c|c|c|c|c|}
\hline Item & Pregnancy loss, \% (n/n) & $\mathrm{AOR}^{1}$ & $95 \% \mathrm{CI}^{2}$ & $P$-value \\
\hline \multicolumn{5}{|l|}{$\mathrm{BCS}$ at $\mathrm{AI}$} \\
\hline$>3.25$ & $26.9(7 / 26)$ & 2.59 & $0.85,7.92$ & 0.04 \\
\hline $2.75-3.25$ & $15.0(15 / 100)$ & 1.00 & - & \\
\hline$<2.75$ & $31.4(11 / 35)$ & 3.34 & $1.27,8.82$ & \\
\hline \multicolumn{5}{|c|}{ Ovulation to final $\mathrm{GnRH}^{3}$} \\
\hline Yes & $18.5(28 / 151)$ & 0.25 & $0.06,1.00$ & 0.05 \\
\hline No & $50.0(5 / 10)$ & 1.00 & - & \\
\hline \multicolumn{5}{|c|}{ Heat stress ${ }^{4}$} \\
\hline Yes & $55.6(5 / 9)$ & 7.42 & $1.71,32.14$ & 0.007 \\
\hline No & $18.4(28 / 152)$ & 1.00 & & \\
\hline
\end{tabular}

${ }^{1} \mathrm{AOR}=$ adjusted odds ratio.

${ }^{2} \mathrm{CI}=$ confidence interval.

${ }^{3}$ Ovulation detected within $48 \mathrm{~h}$ of the final GnRH injection of the Ovsynch protocol.

${ }^{4}$ Heat stress $=$ cows inseminated in the weeks when the daily mean temperature-humidity index $\geq 72$. 
involution (Harrison et al., 1986; Trinder et al., 1973), and Se concentrations in blood were associated with improved neutrophil function (Cebra et al., 2003). Although Se status influences uterine health presumably by affecting immune cells, altering the source of Se in the diet of transition cows did not influence the prevalence of subclinical endometritis at $35 \mathrm{~d}$ postpartum, resumption of cyclicity, or fertility responses of lactating dairy cows in the current study. A possible explanation for the lack of Se source effects is that cows in both dietary treatments had adequate Se concentrations in blood plasma, and feeding SY did not improve Se status throughout the transition period to ameliorate uterine health and reproductive responses of cows. In fact, GPx activity in plasma and neutrophil function were not altered by source of Se (Rutigliano et al., 2006). Because dietary ingredients had considerable concentrations of Se (Rutigliano et al., 2006), which is mostly in organic forms, and both diets had greater than expected concentrations of Se, cows in both dietary treatments had plasma Se concentrations greater than $0.08 \mu \mathrm{g} / \mathrm{mL}$ throughout the postpartum period indicative that Se statuses were adequate (Dargatz and Ross, 1996). It is possible that diets containing $0.5 \mathrm{mg} / \mathrm{kg}$ of Se might mask any beneficial effects of source of Se on reproduction.

When cows were fed sodium selenate or Se-yeast from $60 \mathrm{~d}$ prepartum to $30 \mathrm{DIM}$, immunological responses were not influenced by source of Se (Weiss and Hogan, 2005). On the other hand, replacing SS with $\mathrm{SY}$ in the diets containing $<0.4 \mathrm{mg} / \mathrm{kg}$ of Se improved plasma Se concentrations and reduced the risk for some uterine problems postpartum (Silvestre et al., 2006). Therefore, lack of improvements in reproductive performance when cows were fed different sources of Se likely reflect the inability of Se-yeast to alter immune response and overall periparturient health when diets contained at least $0.4 \mathrm{mg} / \mathrm{kg}$ of Se and plasma Se concentrations were above those considered adequate for cattle (Dargatz and Ross, 1996).

Incidence of subclinical endometritis in the present study was less than previously reported. Kasimanickam et al. (2004) observed that approximately 45.1 and $41.4 \%$ of the cows at 20 to 33 DIM and at 34 to 47 DIM, respectively, had subclinical endometritis. Differences in the prevalence of subclinical endometritis between herds were observed by Gilbert et al. (2005), and prevalence ranged from 37 to $74 \%$ of cows. A possible reason for differences in prevalence may be the distinct techniques used, as it has been demonstrated that the cytobrush technique yields a greater proportion of polymorphonuclear cells compared with the uterine lavage technique when performed between 20 and $33 \mathrm{~d}$ after parturition (Kasimanickam et al., 2005).
Nevertheless, subclinical endometritis negatively influenced pregnancy per AI of dairy cows. Others have also shown marked decreases in risk of pregnancy and extended days open in cows diagnosed with subclinical endometritis anytime after $20 \mathrm{~d}$ postpartum (Kasimanickam et al., 2004; Gilbert et al., 2005). The exact mechanism by which subclinical endometritis influences establishment of pregnancy is unknown, but the negative effects on fertility might be related to reduced fertilization (Cerri et al., 2006), or possibly presence of an uterine environment that is less conducive for adequate embryo development.

Cows presynchronized with a CIDR insert had a larger ovulatory follicle at the $\mathrm{PGF}_{2 \alpha}$ and $\mathrm{GnRH}$ injections of the Ovsynch and were more likely to ovulate in response to the first GnRH of the protocol. The progesterone from the CIDR insert blocks the LH surge during treatment (Sirois and Fortune, 1990), which is expected to more precisely synchronize estrus and, subsequently, ovulation. Previous studies have demonstrated that addition of a CIDR to an estrous synchronization with $\mathrm{PGF}_{2 a}$ resulted in an altered pattern of estrous expression, with tighter synchronization compared with $\mathrm{PGF}_{2 \alpha}$ alone (Chebel et al., 2006). Therefore, the majority of the cyclic cows in the CIDR-PS were in proestrus at the initiation of the Ovsynch protocol, which should favor ovulatory response to GnRH (Vasconcelos et al., 1999; Cerri et al., 2006). Cows in early to mid diestrus and proestrus at initiation of the Ovsynch experience increased incidence of ovulation to a $\mathrm{GnRH}$ injection (Vasconcelos et al., 1999).

Lactating dairy cows that did not ovulate to the first GnRH injection of the Ovsynch protocol had ovulatory follicles with an extended period of dominance, compromised embryo quality (Cerri et al., 2005), and reduced pregnancy per AI (Chebel et al., 2006). Therefore, it was expected that the increased incidence of ovulation in response to the first GnRH of the Ovsynch protocol in the CIDR-PS treatment would result in increased pregnancy per AI. Nonetheless, pregnancy per AI did not differ between Presynch and CIDR-PS. It is possible that the lack of difference in pregnancy after first postpartum TAI was a result of ovulation of follicles from different follicular waves in the Presynch and CIDR-PS. Cyclic cows in the Presynch likely ovulated a second-wave follicle at induction of ovulation to the second injection of GnRH as most of them were expected to be on estrous cycle d 6 to 10 when the first GnRH of the Ovsynch was given (Moreira et al., 2001). On the other hand, CIDR-PS cows ovulated a first-wave follicle following the second injection of $\mathrm{GnRH}$ of the Ovsynch protocol.

Reduced concentrations of progesterone are associated with increased pulse frequency of LH (Bergfeld et 
al., 1996). Because the concentrations of progesterone during the first follicular wave are lower than those during the second or third follicular waves, the concentration of LH during the first follicular wave is greater than in subsequent waves of follicle development (Kulick et al., 2001). Reduced progesterone concentrations should then favor faster follicle growth. In support of this concept, the ovulatory follicle was larger during the Ovsynch protocol in cows receiving the CIDR-PS compared with Presynch, in spite of a greater ovulatory response at initiation of the synchronization program. Furthermore, CIDR-PS cows had increased estradiol concentrations at the injections of $\mathrm{PGF}_{2 \alpha}$ and $\mathrm{GnRH}$ of the Ovsynch, which is associated with reduced concentrations of progesterone and larger follicles. Potential implications are that a first-wave follicle may not offer optimum fertility because it grows under a lower concentration of progesterone and increased pulse frequency of $\mathrm{LH}$, which might compromise the oocyte. Another possibility is that the reduced concentrations of progesterone during Ovsynch in cows receiving CIDR-PS may influence the uterine environment post-AI and subsequent fertility. Recent data from our laboratory indicated that fertility is compromised when cyclic cows received TAI after induction of ovulation of a first-wave follicle (J. E. P. Santos; unpublished results). Studies with lactating dairy cows in New Zealand indicated that 2 injections of $\mathrm{PGF}_{2 \alpha} 13 \mathrm{~d}$ apart reduced pregnancy per AI compared with untreated cows particularly when the second $\mathrm{PGF}_{2 \alpha}$ was given during early (d 5 to 9 ) diestrus (Xu et al., 1997). In those cows, progesterone from an intravaginal insert reestablished normal fertility. Exposure to progesterone in the cycle preceding $\mathrm{AI}$ is important to block premature expression of the luteolytic signal (Zollers et al., 1993). Thus, it is plausible to suggest that synchronization protocols that result in ovulation to the first follicular wave, when the dominant follicle grows under low systemic concentrations of progesterone, may not be optimal for fertility and, in the current study, may have abolished the benefits of greater ovulation to the first GnRH during the Ovsynch protocol.

It is noteworthy that cows receiving CIDR-PS not only had increased incidence of ovulation to the first GnRH, but they also had greater incidence of double ovulation to the final GnRH of the Ovsynch protocol, both factors associated with increased pregnancy per AI. Kulick et al. (2001) demonstrated that codominant follicles occurred more frequently during the first follicular wave than during other waves of follicle growth, and the development of codominant follicles was preceded, on average, by a transient increase in concentrations of LH $24 \mathrm{~h}$ before the expected beginning of deviation. This could account for the greater incidence of double ovulation observed for cows in the CIDR-PS compared with cows receiving Presynch. A greater proportion of multiparous cows had double ovulation, which is in agreement with previous studies that demonstrated that second-lactation cows had 6 to $7 \%$ of twin births compared with only about $1 \%$ twin births for first-lactation cows (Ryan and Boland, 1991). Because multiparous cows produced more milk than primiparous cows (Rutigliano et al., 2006), and milk yield with an associated increase in DM intake is a major risk factor for multiple ovulation (Wiltbank et al., 2006), it is expected that codominance and multiple ovulation will be more prevalent in multiparous than in primiparous cows.

Regardless of presynchronization treatment, cows that ovulated in response to the first $\mathrm{GnRH}$ were more likely to ovulate to the final GnRH of the Ovsynch protocol. This agrees with a previous study that demonstrated that ovulation to the final GnRH of the Ovsynch increased from 79 to $92 \%$ if cows ovulated to the initial GnRH injection (Vasconcelos et al., 1999).

The proportion of cyclic cows was less for CIDR-PS than for Presynch. Treatment with a CIDR insert results in inhibition of expression of estrus and ovulation in cows (Sirois and Fortune, 1990; Chebel et al., 2006). Cows in the CIDR-PS group received a CIDR insert for $7 \mathrm{~d}$ during the 12-d interval between the 2 ultrasonographic examinations to evaluate cyclicity; therefore, cows in the CIDR-PS that did not have a CL at the first evaluation had only $5 \mathrm{~d}$ between the 2 ultrasound examinations to ovulate and be considered cyclic, whereas cows receiving Presynch had $12 \mathrm{~d}$ to ovulate, which might explain the difference in proportion of cyclic cows. Another possibility is that cows in the CIDRPS had 3 fewer days postpartum at ultrasound evaluations, and time postpartum influences resumption of ovulation. Cows at $\mathrm{AI}$ with $\mathrm{BCS} \geq 2.75$ were more likely to be cyclic than those with BCS $<2.75$. This relationship between increased prevalence of cyclic cows with increased BCS has been demonstrated before (Moreira et al., 2001; Chebel et al., 2006). Body condition is correlated with body reserves, in particular body fat (Ferguson et al., 1994), and increased body fatness indicates improved energy reserves that might signal for an earlier resumption of ovarian activity. Cyclic cows were more likely to be pregnant at first AI, which agrees with findings by others (Moreira et al., 2001; Chebel et al., 2006).

Lack of ovulation within $48 \mathrm{~h}$ of the last injection of GnRH of the Ovsynch protocol reduced the risk for pregnancy and increased that of pregnancy loss. Saacke et al. (2000) indicated that insemination early after onset of estrus reduced fertilization, which is expected to compromise fertility. Furthermore, lack of ovula- 
tion within $48 \mathrm{~h}$ is expected to reduce pregnancy per AI particularly if cows fail to ovulate even after $48 \mathrm{~h}$ of the GnRH injection. Interestingly, pregnancy losses increased in cows with ovulation after $48 \mathrm{~h}$ of the final $\mathrm{GnRH}$ of the TAI protocol. It is possible that extended exposure to estradiol and LH during proestrus might have influenced subsequent embryo viability. Also, extended interval between AI and ovulation might have resulted in aged spermatozoa with DNA damage that might compromise subsequent embryo viability. In fact, when cows received AI earlier than $24 \mathrm{~h}$ before ovulation, embryo quality decreased compared with cows receiving AI between 12 and $24 \mathrm{~h}$ from AI (Roelofs et al., 2006). Therefore, the prolonged period for which the spermatozoa have to reside in the reproductive tract of cows might compromise embryo quality and increase incidence of pregnancy loss in cattle. Also, ovulation after $48 \mathrm{~h}$ might have influenced quality of the oocyte because of extended dominance, reducing embryo quality (Cerri et al., 2005; Roelofs et al., 2006).

In addition to ovulatory responses, exposure to heat stress in the week of TAI reduced the risk of pregnancy and increased that of pregnancy loss. Lactating dairy cows suffer from heat stress when the THI is $\geq 72$ (Armstrong, 1994), although it is possible that effects on reproduction might be observed at lower values. In the current study, the average mean daily THI during the period of heat stress was always greater than 72 and it averaged 74.7, whereas during the period of thermoneutrality, it averaged 62 . High temperatures have deleterious effects on steroidogenesis, oocyte quality, fertilization, and on the embryo at early stages of development (Wolfenson et al., 2000), and these effects ultimately influence establishment and maintenance of pregnancy in dairy cows.

\section{CONCLUSIONS}

Source of Se supplemented at $0.3 \mathrm{mg} / \mathrm{kg}$ of diet DM, when diets contained approximately 0.4 to $0.5 \mathrm{mg} / \mathrm{kg}$ of Se, did not influence uterine health and reproductive performance of dairy cows. Cows presynchronized with a CIDR insert and an injection of $\mathrm{PGF}_{2 \alpha}$ at insert removal $3 \mathrm{~d}$ before initiating the Ovsynch protocol had increased incidence of ovulation to the first $\mathrm{GnRH}$ of Ovsynch, larger ovulatory follicles with increased concentrations of estradiol, and a greater incidence of double ovulation to the final GnRH injection before TAI. Although ovulation to the first GnRH and double ovulation to the final GnRH of the Ovsynch protocol increased pregnancy rate, the CIDR-presynchronization treatment had no effect on pregnancy per AI and pregnancy loss compared with cows presynchronized with $\mathrm{PGF}_{2 \alpha}$ alone.

\section{ACKNOWLEDGMENTS}

The authors thank Oscar Rodriguez and the staff of Corcoran State Prison dairy for use of their cows and facilities. Financial support for this project was provided by Alltech Biotechnology (Nicholasville, KY).

\section{REFERENCES}

Armstrong, D. V. 1994. Heat stress interaction with shade and cooling. J. Dairy Sci. 77:2044-2050.

Bergfeld, E. G. M., F. N. Kojima, A. S. Cupp, M. E. Wehrman, K. E. Peters, V. Mariscal, T. Sanchez, and J. E. Kinder. 1996. Changing dose of progesterone results in sudden changes in frequency of luteinizing hormone pulses and secretion of 17 beta-estradiol in bovine females. Biol. Reprod. 54:546-553.

Caraviello, D. Z., K. A. Weigel, P. M. Fricke, M. C. Wiltbank, M. J. Florent, N. B. Cook, K. V. Nordlund, N. R. Zwald, and C. L. Rawson. 2006. Survey of management practices on reproductive performance of dairy cattle on large US commercial farms. J. Dairy Sci. 89:4723-4735.

Cebra, C. K., J. R. Heidel, R. O. Crisman, and B. V. Stang. 2003. The relationship between endogenous cortisol, blood micronutrients, and neutrophil function in postparturient Holstein cows. J. Vet. Intern. Med. 17:902-907.

Cerri, R. L. A., H. M. Rutigliano, R. G. S. Bruno, R. C. Chebel, and J. E. P. Santos. 2005. Effect of artificial insemination (AI) protocol on fertilization and embryo quality in high-producing dairy cows. J. Dairy Sci. 88(Suppl. 1):86. (Abstr.)

Cerri, R. L. A., H. M. Rutigliano, F. S. Lima, D. S. Brito, J. Hillegass, W. W. Thatcher, and J. E. P. Santos. 2006. Effect of source of supplemental Se on uterine health and embryo quality in highproducing dairy cows. J. Dairy Sci. 89(Suppl. 1):53. (Abstr.)

Chebel, R. C., J. E. P. Santos, R. L. A. Cerri, H. M. Rutigliano, and R. G. S. Bruno. 2006. Reproductive performance of lactating dairy cows following progesterone insert based presynchronization and resynchronization protocols. J. Dairy Sci. 89:4205-4219.

Dargatz, D. A., and P. F. Ross. 1996. Blood selenium concentrations in cows and heifers on 253 cow-calf operations in 18 states. J. Anim. Sci. 74:2891-2895.

Ferguson, J. D., D. T. Galligan, and N. Thomsen. 1994. Principal descriptors of body condition score in Holstein cows. J. Dairy Sci. 77:2695-2703.

Gilbert, R. O., S. T. Shin, C. L. Guard, H. N. Erb, and M. Frajblat. 2005. Prevalence of endometritis and its effects on reproductive performance of dairy cows. Theriogenology 64:1879-1888.

Harrison, J. H., D. D. Hancock, N. St Pierre, H. R. Conrad, and W. R. Harvey. 1986. Effect of prepartum selenium treatment on uterine involution in the dairy cow. J. Dairy Sci. 69:1421-1425.

Kasimanickam, R., T. Duffield, R. Foster, C. Gartley, K. Leslie, J. Walton, and W. Johnson. 2004. Endometrial cytology and ultrasonography for the detection of subclinical endometritis in postpartum dairy cows. Theriogenology 62:9-23.

Kasimanickam, R., T. F. Duffield, A. F. Robert, J. G. Cathy, K. E. Leslie, J. S. Walton, and W. H. Johnson. 2005. A comparison of the cytobrush and uterine lavage techniques to evaluate endometrial cytology in clinically normal postpartum dairy cows. Can. Vet. J. 46:255-259.

Kirby, C. J., M. F. Smith, D. H. Keisler, and M. C. Lucy. 1997. Follicular function in lactating dairy cows treated with sustainedrelease bovine somatotropin. J. Dairy Sci. 80:273-285.

Kulick, L. J., D. R. Bergfelt, K. Kot, and O. J. Ginther. 2001. Follicle selection in cattle: Follicle deviation and codominance within sequential waves. Biol. Reprod. 65:839-846.

Moreira, F., C. Orlandi, C. A. Risco, R. Mattos, F. Lopes, and W. W. Thatcher. 2001. Effects of presynchronization and bovine somatotropin on pregnancy rates to a timed artificial insemination protocol in lactating dairy cows. J. Dairy Sci. 84:1646-1659. 
National Research Council. 2001. Nutrient Requirements of Dairy Cattle. 7th rev. ed. Natl. Acad. Press, Washington, DC.

NOAA (National Oceanic and Atmospheric Administration). 1976. Livestock hot weather stress. Pages 31-37. US Dept. Commerce, Natl. Weather Serv. Central Reg., Reg. Operations Manual Lett. NOAA, Washington, DC.

Ortman, K., and B. Pehrson. 1999. Effect of selenate as a feed supplement in dairy cows in comparison to selenite and selenium yeast. J. Anim. Sci. 77:3365-3370.

Phyllis, A. W., and D. E. Ullrey. 1978. Improved fluorometric method for determining selenium. J. AOAC 4:927-930.

Pursley, J. R., M. R. Kosorok, and M. C. Wiltbank. 1997. Reproductive management of lactating dairy cows using synchronization of ovulation. J. Dairy Sci. 80:301-306.

Roelofs, J. B., W. A. M. Graat, E. Mullaart, N. M. Soede, W. VoskampHarkema, and B. Kemp. 2006. Effects of insemination-ovulation interval on fertilization rates and embryo characteristics in dairy cattle. Theriogenology 66:2173-2181.

Rutigliano, H. E., R. L. A. Cerri, F. S. Lima, L. F. Vettorato, D. B. Araujo, J. Hillegass, W. W. Thatcher, and J. E. P. Santos. 2006. Effects of source of supplemental Se on health and immune status of periparturient dairy cows. J. Dairy Sci. 89(Suppl. 1):165. (Abstr.)

Ryan, D. P., and M. P. Boland. 1991. Frequency of twin births among Holstein-Friesian cows in a warm dry climate. Theriogenology $36: 1-10$.

Saacke, R. G., J. C. Dalton, S. Nadir, R. L. Nebel, and J. H. Bame. 2000. Relationship of seminal traits and insemination time to fertilization rate and embryo quality. Anim. Reprod. Sci. 6061:663-677.

Silvestre, F. T., D. T. Silvestre, J. E. P. Santos, C. Risco, C. R. Staples, and W. W. Thatcher. 2006. Effects of selenium (Se) sources on dairy cows. J. Anim. Sci. 84(Suppl. 1):141. (Abstr.)
Sirois, J., and J. E. Fortune. 1990. Lengthening the bovine estrous cycle with low levels of exogenous progesterone: A model for studying ovarian follicular dominance. Endocrinology 127:916925.

Trinder, N., R. J. Hall, and C. P. Renton. 1973. The relationship between the intake of selenium and vitamin $\mathrm{E}$ on the incidence of retained placenta in dairy cows. Vet. Rec. 93:641-643.

Vasconcelos, J. L. M., R. W. Silcox, G. J. M. Rosa, J. R. Pursley, and M. C. Wiltbank. 1999. Synchronization rate, size of the ovulatory follicle, and pregnancy rate after synchronization of ovulation beginning on different days of the estrous cycle in lactating dairy cows. Theriogenology 15:1067-1078.

Weiss, W. P., and J. S. Hogan. 2005. Effect of selenium source on selenium status, neutrophil function, and response to intramammary endotoxin challenge of dairy cows. J. Dairy Sci. 88:4366-4374.

Wiltbank, M., H. Lopez, R. Sartori, S. Sangsritavong, and A. Gumen. 2006. Changes in reproductive physiology of the lactating dairy cow due to elevated steroid metabolism. Theriogenology 65:1729 .

Wolfenson, D., Z. Roth, and R. Meidan. 2000. Impaired reproduction in heat-stressed cattle: Basic and applied aspects. Anim. Reprod. Sci. 60-61:535-547.

Xu, Z. Z., L. J. Burton, and K. L. Macmillan. 1997. Reproductive performance of lactating dairy cows following estrus synchronization regimens with $\mathrm{PGF}_{2 a}$ and progesterone. Theriogenology 47:687-701.

Zollers, W. G. Jr, H. A. Garverick, M. F. Smith, R. J. Moffatt, B. E. Salfen, and R. S. Youngquist. 1993. Concentrations of progesterone and oxytocin receptors in the endometrium of postpartum cows expected to have a short or normal oestrous cycle. J. Reprod. Fertil. 97:329-337. 